\title{
CURVA DE EMBEBIÇÃO PARA SEMENTES DE CHICÓRIA DA AMAZÔNIA
} (Eryngium foetidum L.)

Patrícia de Souza Soares ${ }^{1}$, Larissa da Fonseca Moraes ${ }^{2}$, Erika Soares Gomes ${ }^{1}$, Rafaelle Fazzi Gomes ${ }^{3}$

${ }^{1}$ Engenheira Agrônoma, Universidade Federal Rural da Amazônia, Capanema, PA, Brasil;

${ }^{2}$ Discente de Biologia Bacharelado, Universidade Federal Rural da Amazônia, Capanema, PA, Brasil; e-mail: larissamoraes9815@gmail.com;

${ }^{3}$ Docente, Universidade Federal Rural da Amazônia, Capanema, PA, Brasil.

Recebido em: 06/04/2019 - Aprovado em: 10/06/2019 - Publicado em: 30/06/2019

DOI: 10.18677/EnciBio_2019A44

\begin{abstract}
RESUMO
A chicória (Eryngium foetidum L.) pertencente à família Apiaceae, é uma hortaliça muito consumida na região norte do Brasil, entretanto apresenta carência de pesquisas relacionadas ao processo germinativo. Por isso, este trabalho objetivou determinar a curva de embebição para a chicória da Amazônia. Para isso, a espécie foi cultivada em ambiente protegido, para obtenção de sementes, e posterior montagem do experimento da curva de embebição. Utilizou-se um lote obtido em maio de 2017. O teste foi realizado no laboratório multidisciplinar, da UFRA/Capanema. As sementes foram homogeneizadas, determinando-se o teor de água pelo método em estufa a $105 \pm 3^{\circ}$ por 24 horas, com duas repetições de 100 sementes. A curva foi elaborada a partir de quatro repetições de 100 sementes colocadas para embeber em caixa do tipo "gerbox", tendo como substrato três folhas de papel germitest, saturadas com água destilada. Em seguida, destinadas para câmara de germinação do tipo B.O.D., à temperatura constante de $27^{\circ} \mathrm{C}$ e umidade relativa a $80 \%$. A curva foi determinada por pesagens em intervalos sistematizados, até a protrusão da raiz primária de pelo menos $50 \%$ das sementes. Observou-se uma rápida absorção de água pelas sementes nas primeiras seis horas de embebição, caracterizando o término da fase I às 144 horas, a fase II encontra-se no intervalo de 144 a 288 horas e a fase III caracterizada com emissão da radícula às 336 horas de embebição. A partir dos resultados obtidos, temos que a chicória da Amazônia apresentou um padrão trifásico no seu processo de embebição.
\end{abstract}

PALAVRAS CHAVE: Fases da germinação, fisiologia de sementes, hortaliças

\section{IMBIBITION CURVE FOR SEEDS AMAZONIAN CHICORY (Eryngium foetidum} L.)

\begin{abstract}
The chicory (Eryngium foetidum L.) belonging to the family Apiaceae, is a very consumed vegetable in the northern region of Brazil, however it lacks research related to the germination process. Therefore, this work aimed to determine the soaking curve for Amazonian chicory. For this, the species was cultivated in
\end{abstract}


protected environment, to obtain seeds, and later assembly of the experiment of the embedding curve. A batch obtained in May 2017 was used. The test was carried out in the UFRA / Capanema multidisciplinary laboratory. The seeds were homogenized and the water content was determined by the greenhouse method at $105 \pm 3^{\circ}$ for 24 hours, with two replicates of 100 seeds. The curve was elaborated from four replicates of 100 seeds placed to be soaked in a gerbox type box, having as substratum three sheets of germitest paper, saturated with distilled water. Then, destined for germination chamber type B.O.D., at a constant temperature of $27^{\circ} \mathrm{C}$ and relative humidity at $80 \%$. The curve was determined by weighing at systematized intervals until protrusion of the primary root of at least $50 \%$ of the seeds. A rapid absorption of water by the seeds was observed in the first six hours of imbibition, characterizing the end of phase I at 144 hours, phase II being in the range of 144 to 288 hours and phase III characterized with emission of the radicle at 336 hours of soaking. From the results obtained, we have that the Amazonian chicory presented a three-phase pattern in its imbibition process.

KEYWORDS: stages of germination, seed physiology, vegetables

\section{INTRODUÇÃO}

A chicória da Amazônia, Eryngium foetidum L., é uma espécie da família Apiaceae, com porte herbáceo, bianual, de $8-40 \mathrm{~cm}$ de altura, conhecida por ser nativa da América Central e Latina, muito consumida na região norte do Brasil. Em alguns lugares é também conhecida como chicória do Pará, chicória da Amazônia, coentrão, culantro, nhambi ou como coentro selvagem (GOMES et al., 2013).

Esta espécie é adaptada a temperaturas altas, umidade relativa e chuvas, condições estas que são predominantes na região amazônica, exigindo solos com acidez baixa, e boa disponibilidade de água (VILLACHICA et al., 1996). Nos últimos anos, E. foetidum L. foi incluída entre as principais hortaliças não convencionais cultivadas em nosso país (BRASIL, 2010).

Tendo em vista que o processo de germinação é uma fase de considerável importância no ciclo de vida do vegetal, caracterizado pela embebição de água pelas sementes, um dos fatores que mais influencia no processo de germinação das sementes é a disponibilidade de água. Pois, através da absorção de água ocorre a reidratação dos tecidos, a natural intensificação da respiração e das demais atividades metabólicas, que resultam no fornecimento de energia e de nutrientes necessários para o desenvolvimento do eixo embrionário, além de contribuir para o aumento da porcentagem de germinação (CARVALHO; NAKAGAWA, 2012; ARAÚJO et al., 2018; SOUZA et al., 2018).

Outra questão de relevância é o possível mecanismo de dormência química presente nas sementes desta cultura, o que ocasiona baixa taxa germinativa, mesmo em condições consideradas adequadas (SAMPAIO et al., 2015), sendo possivelmente influenciado pela presença de substâncias inibidoras nas sementes. Neste contexto, Mozumder et al. (2017) avaliando a germinação de sementes de chicória relataram a presença do composto fenólico cumarina sendo responsável pelas baixas taxas de germinação da cultura.

Sendo assim, o processo de embebição de água pelas sementes, acontece de acordo com um padrão trifásico, onde na fase I ocorre o efeito das forças matriciais; a fase II é estacionária, e também é a junção do balanço entre o potencial osmótico e o potencial de pressão e, no início da fase III, acontece à emissão da raiz primária (PIMENTA et al., 2014). Por este motivo a curva de embebição é uma ferramenta fundamental na identificação de sementes que apresentam alguma 
restrição no processo germinativo, como por exemplo, tipos de dormência, pois é neste momento, que sementes consideradas "dormentes" não apresentam o padrão trifásico, permanecendo assim na fase II (ATAIDE et al., 2014; GUOLLO et al., 2016).

Visto que o conhecimento das condições ideais para a germinação de sementes, bem como a caracterização do processo germinativo serem relevantes para compreender as respostas diferenciadas que possam apresentar em função de fatores ambientais e genéticos, além de pesquisas relacionadas à germinação da chicória ainda serem escassas, este trabalho teve como objetivo determinar a curva de embebição para sementes de chicória da Amazônia.

\section{MATERIAL E MÉTODOS}

O estudo foi conduzido no Setor de Olericultura, localizado na Fazenda Escola de Igarapé Açu - FEIGA (0107'48,47'S e 47운'45,31'W, com altitude de 54 $\mathrm{m})$, para a obtenção das sementes, em casa de vegetação e no laboratório multidisciplinar da Universidade Federal Rural da Amazônia, localizado no Município de Capanema-PA (0111'45"S e 47ำ10'51'W, com altitude de $24 \mathrm{~m}$ ), para a determinação da curva.

O delineamento experimental utilizado foi em blocos ao acaso, com seis repetições, contendo 20 plantas por parcela, considerando como área útil as 10 plantas centrais. As sementes foram semeadas em bandejas de poliestireno de 128 células, tendo como substrato composto orgânico. Foram semeadas cinco sementes por célula e após a emergência foi realizada a repicagem, permanecendo apenas uma plântula por célula.

Ao $52^{\circ}$ dia após a semeadura, as mudas de chicória foram transplantadas para canteiros com dimensões $5 \mathrm{~m} \times 1 \mathrm{~m}$, adubados previamente com composto orgânico, utilizando o espaçamento entre plantas de 0,2 $\mathrm{m} \times 0,2 \mathrm{~m}$. A correção do solo e a adubação da cultura foram realizadas de acordo com as recomendações de calagem e adubação para o estado do Pará (CRAVO, et al., 2007).

Com aproximadamente 60 dias após o transplantio, a cultura começou a emitir os primeiros pendões florais e após a maturação das sementes, a qual era identificada quando as inflorescências apresentavam coloração marrom, o pendão floral era cortado com o auxílio de uma tesoura de poda, e em seguida, acondicionado em sacos de papel. Posteriormente, secos em temperatura ambiente e beneficiados manualmente para a retirada das sementes.

Após a obtenção das sementes de chicória da Amazônia foi determinada a curva de embebição. Inicialmente, as sementes foram homogeneizadas e, em seguida, procedeu-se a determinação do teor de água pelo método em estufa a $105 \pm 3^{\circ}$ por 24 horas (BRASIL, 2009) com duas repetições de 100 sementes.

A porcentagem de umidade foi calculada com base no peso úmido da semente, aplicando a Equação1:

$$
\% \text { Umidade }(U)=\frac{100(P-p)}{P-t}
$$

em que:

$\mathrm{P}$ = peso inicial $(\mathrm{g})$, peso do recipiente e sua tampa mais o peso da semente úmida;

$\mathrm{p}=$ peso final $(\mathrm{g})$, peso do recipiente e sua tampa mais o peso da semente seca;

$\mathrm{t}=$ tara $(\mathrm{g})$, peso do recipiente com sua tampa. 
A curva foi elaborada a partir de sementes colocadas para embeber em caixa do tipo "gerbox", tendo como substrato três folhas de papel germitest saturadas com água destilada. A quantidade de água foi determinada utilizando-se 2,5 vezes a massa do papel seco.

Para isso foi utilizada a mistura de sementes, onde foram contabilizadas quatro repetições de 100 sementes. Em seguida, as sementes foram levadas a câmara de germinação do tipo B.O.D. (Biochemical Oxigen Demand) Modelo SL$224 / \mathrm{U}$, regulada para manter a temperatura constante de $27^{\circ} \mathrm{C}$ e umidade relativa a $80 \%$ com fotoperíodo de $12 \mathrm{~h}$, durante todo o experimento.

Inicialmente, as sementes foram pesadas utilizando uma balança analítica de precisão $(0,0001 \mathrm{~g})$ Modelo MARK M 214A, com intervalo de 30 minutos, entre as pesagens, durante as seis primeiras horas de embebição. Após 24 horas da última pesagem, as sementes foram pesadas novamente, mantendo-se este intervalo até o $15^{\circ}$ dia, sendo encerradas após a protrusão da raiz primária de pelo menos $50 \%$ das sementes detectando as fases I, II e III de embebição.

O teor de água das sementes foi calculado de acordo com a Equação 2:

$$
T A=\left(\frac{P f-P i}{P i}\right) \times 100
$$

Em que:

$\mathrm{Pf}=$ peso final, em gramas (ganho de umidade a cada período de embebição);

$\mathrm{Pi}=$ peso inicial, em gramas, das sementes antes da embebição.

Após a obtenção dos dados, estes foram organizados em planilha Excel ${ }^{\circledR}$, sendo gerado gráfico de regressão, com ajuste cúbico, para identificação das fases da germinação.

\section{RESULTADOS E DISCUSSÃO}

O teor de água inicial das sementes do lote utilizado foi de $9 \%$. Na curva de embebição (Figura 1), observa-se o teor de água em função do tempo em horas, onde é possível verificar a evolução do processo germinativo por meio da curva de absorção de água pelas sementes ao longo de 360 horas (15 dias).

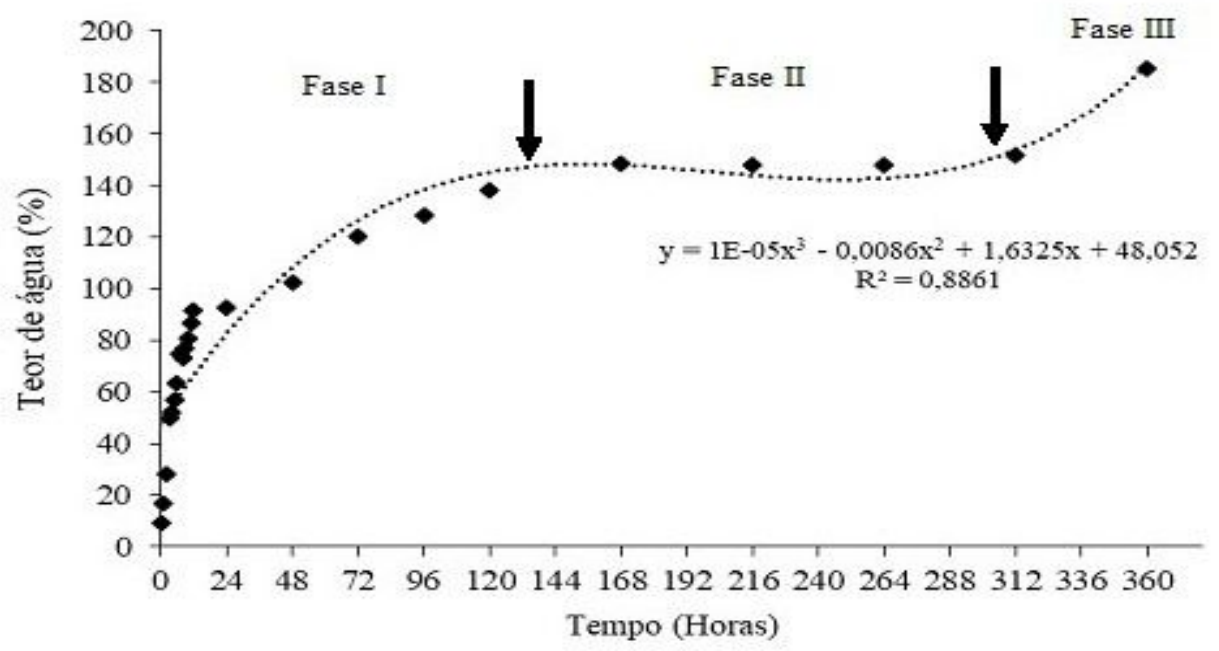

FIGURA 1- Curva de embebição de sementes de chicória da Amazônia, Universidade Federal Rural da Amazônia, Capanema-PA. 
A curva de embebição das sementes de chicória seguiu o padrão trifásico, sendo possível identificar, pontualmente, a transição entre as fases I, II e III da embebição.

$\mathrm{Na}$ fase I, foi observada uma rápida absorção de água nas seis primeiras horas, atingindo em média $62 \%$ de umidade, quando comparado ao peso inicial das sementes. Após 24 horas, o teor de água já estava por volta de $92 \%$. Aproximadamente 144 horas após o início do teste, as sementes apresentavam uma umidade média de $147 \%$, culminando com o término da primeira fase, aos seis dias após o início do experimento, iniciando, assim, a fase II.

$\mathrm{Na}$ fase II de embebição, denominada de estacionária ou de repouso fisiológico, ocorreu uma pausa na absorção de água, característica desta fase, que nas sementes de chicória encontram-se no intervalo de 144 a 288 horas (em média seis dias) da embebição, mantendo a porcentagem de umidade próxima à registrada no final da fase 1 .

Segundo Assis et al. (2012), o nível de absorção de água na fase II pode ser mantido constante ou aumenta gradativamente, por um período conhecido como intervalo ou fase de preparação e ativação do metabolismo. Acrescenta-se ainda, que é nesta fase que as sementes de espécie com dormência diferenciam-se das demais. Em seu trabalho com sementes de coentro, observou-se a presença de dormência, caracterizada pela longa duração da fase II. Em sementes de salsa, pertencente à mesma família da chicória da Amazônia, Sorgatto e Silva (2018) observaram que a fase II começou entre 56,7 e 91,6 horas após o início da embebição.

Vale ressaltar que existem na literatura evidências da presença do composto fenólico denominado cumarina, que apresenta efeito inibitório da germinação, nas sementes de chicória da Amazônia, sendo responsável pelas baixas taxas de germinação, e provável prolongamento na fase II da curva de embebição (MOZUMDER et al., 2016).

Em trabalho realizado por Perez e Moraes (1991), avaliando a interação entre cumarina e giberelina na germinação de sementes de algarobeira (Prosopis juliflora (Sw) DC) pertencente à família Fabaceae, observaram que a aplicação de cumarina alterou de forma geral a porcentagem e a velocidade de germinação das sementes, ocorrendo à completa inibição com utilização de 10,0 mM dessa substância. Entretanto, em baixas concentrações de cumarina (até 5,0 mM) foi possível reverter essa situação, por meio da aplicação de giberelina.

Após o período de absorção reduzida, as sementes voltaram a ganhar umidade, depois de 312 horas de embebição, ou seja, 13 dias, caracterizando o início da fase III, com umidade aproximada de $151 \%$. O início da protrusão da raiz primária ocorreu a partir das 336 horas de embebição (14 dias), finalizando as pesagens com 360 horas (15 dias), apresentando teor de água próximo a 185\%.

$\mathrm{Na}$ curva de embebição realizada por Assis et al. (2012) com sementes de coentro verificou-se que a fase III teve início por volta das 132 horas, mostrando um logo período até o início da germinação. Entretanto, o resultado obtido no presente trabalho, para a chicória, foi de 336 horas até o surgimento da protrusão radicular, demonstrando um período bem mais elevado quando comparado ao do coentro, sendo quase três vezes superior.

Já em trabalho realizado por Correio, Correio e Silva (2017), avaliando lotes de sementes de cenoura em diferentes meios de condicionamento fisiológico e métodos de embebição, observaram o início da protrusão da raiz primária após 54 horas do início da embebição com teor de água de $48,80 \%$, por meio da utilização 
do método de hidrocondicionamento em papel, sendo este responsável pelos melhores resultados na germinação e vigor da cultura, considerado como uma alternativa para aumentar o vigor de lotes de sementes.

Desta forma, entender o comportamento germinativo da semente é importante para compreender a ocupação de uma espécie em determinados ambientes, e de acordo com Melo et al. (2018), a rápida germinação é característica predominante em espécies estrategistas, pois estas aproveitam as condições favoráveis para a sua germinação e desenvolvimento, no entanto, para a chicória da Amazônia, observa-se que a mesma não apresenta o comportamento de espécie estrategista, visto que há uma lenta germinação.

\section{CONCLUSÃO}

A partir dos resultados obtidos, temos que a chicória da Amazônia apresentou um padrão trifásico de embebição, onde a fase I foi caracterizada pela permanência em média de seis dias, seguido da fase II, com média de 13 dias, e concluindo o padrão trifásico com a emissão da radícula, fase III, aos 15 dias.

\section{REFERÊNCIAS}

ARAÚJO, M. L.; MAGALhÃES, A. C. M.; ABREU, M. G. P.; MACIEL, J. A.; FILHO, A. L. M. Efeito de diferentes potenciais osmóticos sobre a germinação e o desenvolvimento de plântulas de feijão enxofre. Ensaios, v. 22, n. 3, p. 201-204, 2018.

Disponível

em:

http://revista.pgsskroton.com.br/index.php/ensaioeciencia/article/view/5935. Acesso em: 11/03/2019. DOI: http://dx.doi.org/10.17921/1415-6938.2018v22n3p201-204

ASSIS, M.O.; RODRIGUES, B.R.A.; DAVID, A.M.S.S.; CANGUSSÚ, L. V. S.; MOTA, W. F. Curva de absorção de água em sementes de coentro. Horticultura Brasileira, Brasília, v. 30, n. 2, p. 7860-7866, 2012. Disponível em: http://www.abhorticultura.com.br/EventosX/Trabalhos/EV_6/A4837_T6647_Comp.pd f. Acesso em: 12/03/2019.

ATAIDE, G. M.; BORGES, E. E. L.; FLORES, A. V.; CASTRO, R. V. O. Avaliação preliminar da embebição de sementes de jacarandá-da-bahia. Pesquisa Florestal Brasileira, Colombo, v. 34, n. 78, p. 133-139, 2014. Disponível em: https://pfb.cnpf.embrapa.br/pfb/index.php/pfb/article/view/520/362. Acesso em: 03/03/2019. DOI: 10.4336/2014.pfb.34.78.520

BRASIL. Ministério da Agricultura e Reforma Agrária. Regras para análise de sementes. Brasília: SNDA/DNDV/CLAV, 2009. Disponível em: http://www.agricultura.gov.br/assuntos/insumos-agropecuarios/arquivos-publicacoesinsumos/2946_regras_analise_sementes.pdf. Acesso em: 11/03/2019.

BRASIL. Ministério da Agricultura, Pecuária e Abastecimento. Manual de hortaliças não convencionais. Secretaria de Desenvolvimento Agropecuário e Cooperativismo. Brasília: Mapa/ACS, 2010. 92 p. Disponível em: http://www.abcsem.com.br/docs/manual_hortalicas_web.pdf. Acesso em: 10/03/2019.

CARVALHO, N. M.; NAKAGAWA, J. Sementes: ciência, tecnologia e produção. 5.ed. Jaboticabal: FUNEP, 2012. 590p. 
CORREIA, D. L. R.; CORREIA, H. M. L.; SILVA, E. E. Embebição e germinação de sementes de cenoura condicionadas fisiologicamente sob situações ambientais adversas. Revista Científica Rural, v. 19, n. 9, p. 205-2015, 2017. ISSN 1413-8263. Disponível em: http://revista.urcamp.tche.br/index.php/rcr/article/view/142/pdf_7. Acesso em: 04/03/2019.

CRAVO, M. S.; VIÉGAS, I. J. M.; BRASIL, E. C. Recomendação de adubação e calagem para hortaliças folhosas. Recomendação de adubação e calagem para 0 Estado do Pará. Belém do Pará: Embrapa Amazônia Oriental, 2007. 187p.

GOMES, R. F.; SILVA, J. P.; GUSMÃO, S. A. L.; SOUZA, G. T. Produção de chicória da Amazônia cultivada sob densidades de cultivo e poda do pendão floral. Revista Catinga, Mossoró, v. 26, n 3, p. 9-14, 2013. ISSN 1983-2125. Disponível em: https://periodicos.ufersa.edu.br/index.php/caatinga/article/view/2573. Acesso em: 10/03/2019.

GOMES, J. P.; OLIVEIRA, L. M.; FERREIRA, P. I.; BATISTA, F. Substratos e temperaturas para teste de germinação em sementes de Myrtaceae. Ciência Florestal, Santa Maria, v. 26, n. 4, p. 285-293, 2016. ISSN 0103-9954. Disponível em: $\quad$ http://www.scielo.br/scielo.php?pid=S198050982016000100285\&script=sci_abstract\&tlng=pt. Acesso em: 15/03/2019. DOI: http://dx.doi.org/10.5902/1980509821120.

GUOLLO, K.; MENEGATTI, R. D.; DEBASTIANI, A. B.; POSSENTI, J.; NAVROSKI, M.C. Biometria de frutos e sementes e determinação da curva de embebição em sementes de Mimosa scabrellal Benth. Revista Cultivando o Saber, v. 9, n. 1, p. 110, 2016. ISSN 2175-2214 Disponível em: https://www.researchgate.net/profile/Renata_Diane_Menegatti/publication/31230430 1_Biometria_de_frutos_e_sementes_e_determinacao_da_curva_de_embebicao_em sementes_de_Mimosa_scabrella_Benth/links/587a173708ae4445c05fac7e/Biometr ia-de-frutos-e-sementes-e-determinacao-da-curva-de-embebicao-em-sementes-deMimosa-scabrella-Benth.pdf. Acesso em: 14/03/2019.

MELO, L. D. F. A.; MELO JUNIOR, J. L. A.; FERREIRA, V. M.; ARAÚJO NETO, J. C.; NEVES, M. I. R. S. Biometric characterization and seed germination of giant mimosa (Mimosa bimucronata (DC) $\mathrm{O}$. Kuntze). Australian Journal of Crop Science, v. 12, p.108-115, 2018. ISSN 1835-2707. Disponível em: http://www.cropj.com/melo_12_1_2018_108_115.pdf. Acesso em: 03/03/2019. DOI: 10.21475/adjcs.18.12.01.pne773

MOZUMDER, S. N.; HOSSAIN, M. M.; AKTER, S. Influence of seed treatment and priming on growth performance of Eryngium foetidum. International Journal of Advanced Research in Biological Sciences, Índia, v.3, n. 6, p. 113-122, 2016. ISSN 2348-8069. Disponível em: https://www.ijarbs.com/pdfcopy/june2016/ijarbs15.pdf. Acesso em: 13/03/2019.

MOZUMDER, S. N.; HAQUE, M. I.; KAMAL, M. M.; AKTER, S.; BANIK, B. R. Effect of storage, growth regulator treatment and seed priming on germination of Eryngium foetidum L. International Journal of Advanced Multidisciplinary Research, Índia, v. $4, \quad$ n. $7, \quad$ p. 16-21, 2017. Disponível em: 
http://ijarm.com/pdfcopy/july2017/ijarm4.pdf. Acesso em: 12/03/2019. DOI: 10.22192/ijamr

PEREZ, S. C. J. G. A.; MORAES, J. A. P. V. Efeito da cumarina e de sua interação com giberelina na germinação de Prosopis juliflora (Sw) DC. Pesquisa Agropecuária Brasileira, Brasília, v. 26, n. 9, p. 1493-1501, 1991. Disponível em: http://ainfo.cnptia.embrapa.br/digital/bitstream/AI-SEDE/21268/1/pab21_set_91.pdf. Acesso em: 12/03/2019.

PIMENTA, A. C.; ZUFFELLATO-RIBAS, K. C.; LAVIOLA, B. G.; PANOBIANCO, M. Curva de absorção de água em sementes de pinhão-manso. Comunicata Scientiae, Bom Jesus, v. 5, n. 3, p. 295-301, 2014. ISSN 2177-5133. Disponível em: https://comunicatascientiae.com.br/comunicata/article/view/480. Acesso em: 10/03/2019.

SAMPAIO, M. F. et al. Influência de diferentes substratos associados a métodos de superação de dormência na germinação e emergência de sementes de jatobá (Hymenaea courbaril L.). R. Farociência, Porto Velho, v. 2, n. 1, p. 13-27, 2015. ISSN 2359-1846. Disponível em: http://www.faro.edu.br/farociencia/index.php/FAROCIENCIA/article/view/94. Acesso em: 13/03/2019.

SORGATTO, K. P.; SILVA, N. N. Embebição de sementes de salsa com Ascophyllum nodosum: efeitos na germinação e crescimento de plântulas sob estresse térmico. Acta Biológica Catarinense, v. 5, n. 3, p. 99-106, 2018. Disponível em: http://periodicos.univille.br/index.php/ABC/article/view/518. Acesso em: 13/03/2019. DOI: http://dx.doi.org/10.21726/abc.v5i3.518

SOUZA, P. A.; SANTOS, A. F.; GONÇALVES, D. S.; VENTURIN, N. Efeito da reidratação na germinação de sementes de açaí (Euterpe oleraceae Mart.). Revista de Ciências Agroveterinárias, v.17, n. 2, p. 286-291, 2018. Disponível em: http://www.revistas.udesc.br/index.php/agroveterinaria/article/view/8394. Acesso em: 10/03/2019. DOI: DOI: 10.5965/223811711722018286

VILLACHICA, H.; CARVALHO, J. E. U.; MULLER, C. H.; DIAZ, S. C.; ALMANZA, M. Frutales y hortalizas promisorios de la Amazônia. Lima: Tratado de cooperacion Amazonica, Secretaria Pro-Tempore Belém, p. 385, 1996. Disponível em: $\quad$ https://pt.scribd.com/doc/25019192/Frutales-y-Hortalizas-Promisorios-de-LaAmazonia. Acesso em: 10/03/2019. 